\title{
Melasma: tratamento e suas implicações estéticas
}

O melasma se caracteriza em uma disfunção estética havendo a necessidade de procurar auxílio de profissionais da saúde estética para o diagnóstico correto e tratamento adequado. Melasma é ocasionada a partir do aumento da melanina na pele, as implicações estéticas se manifestam por manchas escuras ou acastanhadas na região frontal da face. Nesse contexto o estudo será a partir da seguinte questão norteadora: quais os tratamentos utilizados no tratamento do melasma e suas implicações estéticas? O objetivo geral desse estudo é realizar um levantamento bibliográfico sobre o tratamento e as implicações estéticas provocadas pelo melasma. Mediante o exposto, justifica-se a importância de conhecer os aspectos referentes ao Melasma: Tratamentos e suas implicações estéticas, para isso trata-se de uma revisão de literatura, realizada a partir da busca de dados em fontes secundarias como sítios, artigos científicos entre outros. A pele está disposta a danos resultantes do meio externo que resulta em afecções como o melasma e para isso, existem tratamentos estéticos que promovem efeitos positivos promovendo a qualidade de vida das pessoas. $O$ tratamento do melasma pode ser realizado de forma tópico ou oral, a partir de procedimentos que induzem a descamação e removem a cada superficial da pele, promovendo uma textura mais suave e homogênea permitindo a produção de colágeno e elastina com menos riscos de efeitos colaterais. É valido ressaltar que embora existam vários protocolos de tratamento do melasma a eficiência do tratamento é limitada em alguns casos se o paciente não manter uma forma sistemática de prevenção acontece a reincidência do mesmo. 0 melasma pode ser prevenido evitando a exposição solar, nos horários adequados e uso de filtros solares de amplo espectro para radiação UVA e UVB, com fator de proteção solar (FPS) 30 ou mais (MASCENA, 2016).

Palavras-chave: Melasma; Tratamentos estéticos; Pele; Melasma facial.

\section{Melasma: treatment and its aesthetic implications}

Melasma is characterized as an esthetic dysfunction with the need to seek help from esthetic health professionals for the correct diagnosis and proper treatment. Melasma is caused by the increase of melanin in the skin, the aesthetic implications are manifested by dark or brownish spots on the frontal region of the face. In this context, the study will be based on the following guiding question: which treatments are used in the treatment of melasma and their aesthetic implications? The general objective of this study is to carry out a literature review on the treatment and aesthetic implications caused by melasma. Given the above, the importance of knowing the aspects related to Melasma is justified: Treatments and their aesthetic implications, for this it is a literature review, carried out from the search for data in secondary sources such as sites, scientific articles among others. The skin is willing to damage resulting from the external environment that results in conditions such as melasma and for this, there are aesthetic treatments that promote positive effects promoting the quality of life of people. The treatment of melasma can be performed topically or orally, using procedures that induce peeling and remove each surface of the skin, promoting a smoother and more homogeneous texture, allowing the production of collagen and elastin with less risk of side effects. It is worth emphasizing that although there are severa protocols for the treatment of melasma, the treatment efficiency is limited in some cases, if the patient does not maintain a systematic form of prevention, its recurrence occurs. Melasma can be prevented by avoiding sun exposure, at appropriate times and using broad-spectrum sunscreens for UVA and UVB radiation, with a sun protection factor (SPF) of 30 or more (MASCENA, 2016).

Keywords: Melasma; Aesthetic treatments; Skin; Facial Melasma.

Topic: Dermatologia

Reviewed anonymously in the process of blind peer.

\section{Maysa Coelho Borges}

Centro Universitário ITPAC, Brasil

maysinhab@gmail.com
Received: 20/10/2020

Approved: 08/02/2021
Referencing this:

BORGES, M. C.. Melasma: tratamento e suas implicações estéticas. Health of Humans, v.3, n.1, p.8-19, 2021. DOI: http://doi.org/10.6008/CBPC2674-6506.2021.001.0002 


\section{INTRODUÇÃO}

Melasma é ocasionada a partir do aumento da melanina na pele, as implicações estéticas se manifestam por manchas escuras ou acastanhadas na região frontal da face. A pele é o órgão mais sensível do corpo humano, e a cor da pele tem influência a partir da produção de melanina, nesse contexto, todos os tipos de pele estão propícios ao desenvolvimento dos distúrbios pigmentares. A pele possui a função de proteger a pele contra perda de substância e impedir a penetração das mesmas no corpo, histologicamente a mesma é composta por três camadas, epiderme, derme e hipoderme (AMORIM, 2014).

A aparência física tem se tornado cada dia mais um aspecto de importância na sociedade as manchas principalmente as faciais causadas pelo melasma tem causado transtorno e baixa autoestima, segundo Souza et al. (2012) melasma é adquirida a partir de uma hiperpigmentação que aparece nas áreas fotoexpostas da região facial que se caracteriza em manchas simétricas com tonalidades diferentes como marrom, castanhoacinzentadas com características clínicas e histológicas, a localização do pigmento é epidérmico, dérmico ou misto. O melasma tem crescimento gradual e não apresenta sinais típicos de um processo inflamatório, e o mesmo pode se apresentar nos indivíduos de descendência asiática, negra e hispânica é observada com maior frequência (HABIF, 2012; MATOS et al., 2009).

O melasma se caracteriza em uma disfunção estética havendo a necessidade de procurar auxílio de profissionais da saúde estética para o diagnóstico correto e tratamento adequado. O diagnóstico do melasma se baseia no histórico do paciente e nas manifestações clínicas. Nesse contexto o estudo será a partir da seguinte questão norteadora: quais os tratamentos utilizados no tratamento do melasma e suas implicações estéticas? O objetivo geral deste estudo é realizar um levantamento bibliográfico sobre o tratamento e as implicações estéticas provocadas pelo melasma. Os objetivos específicos são: avaliar os efeitos e as implicações estéticas dos tratamentos contra a melasma; verificar os principais recursos utilizados no tratamento do melasma facial.

Mediante o exposto, justifica-se a importância de conhecer os aspectos referentes ao Melasma: Tratamentos e suas implicações estéticas, para isso trata-se de uma revisão de literatura, realizada a partir da busca de dados em fontes secundárias como sítios, artigos científicos entre outros.

\section{METODOLOGIA}

O estudo em questão é uma revisão bibliográfica sobre a temática Melasma: Tratamentos e suas implicações estéticas, a pesquisa foi realizada nos bancos de dados PubMed, Scielo, Periódicos Capes e Google Acadêmico entre outros. Segundo Gil (2010), "as fontes bibliográficas são classificadas em livros de leitura corrente, livros de referência (dicionários, enciclopédias, anuários e almanaques); publicações periódicas (jornais e revistas) e impressos diversos. Para a referida busca utilizou-se as seguintes palavras chave: Melasma. Tratamento. Peeling químicos. Hidroquinona. Ácido glicólico. Microagulhamento. Laser.

Ácido ascórbico ou vitamina C. Ácido Kójico. Os critérios utilizados para seleção dos artigos foram: artigos completos nos idiomas português e inglês. 


\section{DISCUSSÃO TEÓRICA}

\section{Melasma: conceito}

Melasma é um termo grego, "melas" significa negro, é uma hipermelanose de fácil diagnóstico, ocasionada a partir da exposição a Raios UV, dentre outros fatores (NEVES, 2013). Segundo Nicolaidou et al. (2014), o Melasma se caracteriza a partir do surgimento de manchas claras e escuras na região da face, e em alguns casos essas manchas podem se apresentar em outros locais, como braços, pescoço e colo. As manchas são decorrentes da exposição solar a partir de fatores hormonais que promovem a melanina. A Melasma se manifesta por uma dermatose que altera a cor da pele normal resultando na hiperatividade melanocítica, que pode ser alterada no decorrer da gravidez.

Com base nos estudos de Handel et al. (2014), o melasma é uma hipermelanose se caracteriza nas formas simétricas com contornos irregulares e se apresentam com cores nítidas nas áreas fotoexpostas especialmente face. Nesse processo está envolvido a influência hormonal que se associa com o período de gravidez, o uso de contraceptivos orais, terapia de reposição hormonal, radiação ultravioleta A e B, predisposição genética, drogas fototóxicas, anticonvulsivantes e disfunção tireoidiana.

A melanina tem aumento a partir da exposição solar é uma resposta fotoprotetora dos melanócitos e queratinócitos, a mesma acontece a partir de uma cascata de reações químicas que resulta no aumento das expressões de hormônios, principalmente o estimulador de melanócito, a melatonina, com essa exposição em excesso pode causar ou agravar algumas alterações da pigmentação, como o melasma (MIOT et al., 2009).

No Brasil a melasma se apresenta com maior frequência entre as mulheres na idade de 20 a 40 anos ocasionada de uma relação hormonal e sua fisiopatologia (ACHAR et al., 2011; HEXSEL et al., 2013; TAMEGA et al., 2013). A Melasma pode aparecer em ambos os sexos e em todas as etnias. Sendo comum no sexo feminino na fase adulta e fértil, em alguns casos inicia pós-menopausa, dos 30 a 55 anos e o sexo masculino apenas $10 \%$ deles apresenta casos clínicos (CESTARI et al., 2014). As lesões apresentam influência multifatorial, dependendo da interação de elementos ambientais e hormonais, com substrato genético suscetível (NEVES, 2014).

O melasma é mais frequente em mulheres em idade fértil, entre 30 a 55 anos, afetando cerca de 90\% destas, apesar que possa ser visto em homens, sendo eles correspondentes por 10\% dos casos (GAEDTKE, 2011; BRIANEZI, 2016). No Brasil, constitui a terceira causa de doenças dermatológicas, geralmente, manifesta-se em pacientes na idade fértil ( $D^{\prime} E L I A, 2015 ;$ RODRIGUES, 2016).

As melasma são máculas com cores acastanhadas, com contornos irregulares e nítidos, surge a partir da exposição ao sol, principalmente na face e região cervical e de forma menos comum, na região dos braços e esternal. A distribuição das lesões de melasma facial se categoriza nas regiões centrofacial e periférico. 0 melasma da região centrofacial são predominantes no centro da face, ou seja, glebelar, frontal, nasal, zigomático, labial superior, o periférico é pertinente nas regiões fronto -temporais, pré-auriculares e ao longo dos ramos mandibulares (DAYAl et al., 2017). 
Uma das frequentes causas de fazer pacientes procurarem os consultórios dermatológicos é a presença do melasma que se trata de deuma patológica ao grupo das discromias, as cores dos pigmentos das manchas variam de acordo com o fototipo do indivíduo que pode se apresentar em pequenas áreas do rosto ou até total. A lesão surge de forma abrupta, devido a fatores como exposição solar intensa, e tem predominância no sexo feminino (MASCENA, 2016).

Quadro 1: Classificação de Fitzpatrick (adaptada de GAEDKTE, 2011).

\begin{tabular}{|c|c|c|}
\hline Fototipo & Cor da pele & Características \\
\hline Tipo I & Branca, muito clara & $\begin{array}{c}\text { Queima facilmente, nunca } \\
\text { bronzeia }\end{array}$ \\
\hline Tipo II & Branca, clara & $\begin{array}{c}\text { Queima facilmente, } \\
\text { bronzeamento mínimo e com dificuldade }\end{array}$ \\
\hline Tipo III & $\begin{array}{c}\text { Queima moderadamente, } \\
\text { bronzeia moderada e } \\
\text { uniformemente }\end{array}$ \\
\hline Tipo IV & Morena clara & $\begin{array}{c}\text { Queima minimamente, } \\
\text { bronzeia moderada e } \\
\text { facilmente }\end{array}$ \\
\hline Tipo V & Negra & $\begin{array}{c}\text { Queima raramente, bronzeia } \\
\text { profundamente }\end{array}$ \\
\hline Tipo VI & Noranca queima, bronzeia \\
\hline
\end{tabular}

O melasma se classifica em epidérmico dérmico e misto, também como facial e extra facial, e ainda, como leve, moderado ou grave. A mesma pode se classificar a partir de uma distribuição facial de pigmentação, centrofacial (bochechas, testa, lábio superior e nariz), malar (bochechas e nariz) e mandibular (área mandibular das bochechas) (SARKAR et al., 2017). A exposição aos raios UV perfazem a pigmentação da pele, tendo como distúrbios a hiperpigmentação, e os fototipos I-IV. Os raios UVB (290-320 nm), os mais acentuados, promovem danos no DNA por meio da produção de dímeros de pirimidina, ciclobutano e fotoprodutos. Os raios UVA (320-400 nm) tem como causas de produção as espécies reativas de oxigênio, causando danos no DNA. Os raios UVA penetram na pele e atingem tanto a camada basal como a epiderme (NOUVEAU et al.,2016).

\section{Tipos de melasma}

Segundo Pontes et al. (2014), existem três tipos de melasma: Epidérmico: Quando há depósito aumentado de pigmento através da epiderme (camada mais superficial da pele). Dérmico: Caracterizado pelo depósito de melanina ao redor dos vasos superficiais e profundos. Misto: Quando se tem excesso de pigmento na epiderme em certas áreas e na derme em outras regiões. Além de três tipos comuns que são o fácil que se apresenta na região malar, na centrofacial e mandibular. 
Quadro 2: Tipos de Melasma e critérios de diagnóstico adaptada de Becker et al. (2017).

\begin{tabular}{cccc}
\hline Tipo de melasma & Histologia & Luz de Wood & Dermatoscopia \\
\hline Epidérmico & $\begin{array}{c}\text { Aumento da } \\
\text { melanina na } \\
\text { epiderme }\end{array}$ & $\begin{array}{c}\text { Fluorescência } \\
\text { melhorada }\end{array}$ & $\begin{array}{c}\text { Telangiectasia, } \\
\text { pigmento castanho }\end{array}$ \\
Dérmico & Aumento perivascular & $\begin{array}{c}\text { Ausência de } \\
\text { fluorescência }\end{array}$ & Telangiectasia \\
Misto & $\begin{array}{c}\text { Macrófagos, } \\
\text { pigmentação } \\
\text { epidérmica moderada }\end{array}$ & $\begin{array}{c}\text { Açōes com e sem } \\
\text { fluorescência }\end{array}$ & Pigmento azul-cinza \\
\hline
\end{tabular}

\section{Principais tipos de tratamento}

O melasma necessita de tratamento sistemático e contínuo, atualmente existem vários tipos de tratamentos que promovem o clareamento gradual das manchas causada pela melanina. $\mathrm{O}$ tratamento do melasma é realizado com a combinação de fotoproteção, estratégias que reduzam a biossíntese, transporte e transferência da melanina, além de terapias como o peeling, que reduzem quantidade de melanina na epiderme (SANDIN et al., 2014).

Todos os tipos de pele estão propícios aos desenvolvimentos de distúrbios pigmentares que exige a aplicação tópica de agentes despigmentantes como, a hidroquinona, prevenção e proteção solar e às vezes, aplicações de peelings químicos, com o intuito de reduzir a hiperpigmentação, tomando um certo cuidado no clareamento indesejado da pele normal (AVRAM et al., 2018). Nos tópicos seguintes serão citados a importância de alguns tratamentos utilizados na prevenção do melasma.

\section{Peeling químicos}

O peeling provém do inglês "to peel", que pode descamar, pelar, por ser um agente químico em contato com a pele, com o objetivo de provocar a destruição da epiderme ou parte da derme que esfolia e remove as lesões regenerando o tecido. Sendo estes tratamentos contraindicado em casos de gravidez, lactação, infecção bacteriana e fúngica e uso de medicamentos fotossensibilizantes (YOKOMIZO et al., 2013).

Os peelings se classificam em químicos e mecânicos (ALAM et al., 2010). O mecânico é realizado por meio da microdermoabrasão, a esfoliação acontece por meio de equipamentos com uma ponteira de cristal ou diamante que faz o lixamento da pele, esse procedimento é invasivo. $O$ tratamento age de maneira suave e progressiva, pode ser usado em todos os tipos de pele (SBBME, 2015).

\footnotetext{
Os peelings podem ser classificados quanto à profundidade em: - muito superficiais: removem o extrato córneo - profundidade de $0,06 \mathrm{~mm}$; - superficiais: provocam esfoliação epidérmica - da camada granulosa até a basal $(0,45 \mathrm{~mm})$; - médios: atingem a derme papilar $(0,6 \mathrm{~mm}) ;$ - profundos: atingem a derme reticular média $(0,8 \mathrm{~mm})$.

Quanto mais profundos, mais aparentes serão os resultados, porém aumentarão também os riscos e o desconforto no período após o procedimento. (YOKOMIZO et al., 2013)
}

Os peelings químicos superficiais são utilizados há anos no tratamento do melasma, principalmente nos casos refratários (SANDIN et al., 2014). Geralmente, o peeling químico não deve ser usado em indivíduos com pele escura (INGBER, 2009). 
Segundo Marques et al. (2016) “o peeling químico ativa um mecanismo biológico que é capaz de estimular a renovação e o crescimento celular que resultará em uma aparência mais saudável". A pele tem resultados após a descamação, promovendo a renovação da pele a partir de camadas mais profundas, melhorando manchas e rugas, além da melhoria da elasticidade. Existem vários tipos de peelings, sendo eles utilizados há anos no tratamento de melasma, os mesmos possuem princípios ativos que clareiam a pele amenizando as manchas (CAETANO et al., 2013).

\section{Hidroquinona}

A Hidroquinona é um composto orgânico aromático que pertence ao grupo dos fenóis, sendo este um ativo dermatológico despigmentante que apresenta ação inibitória reversível da enzima tirosinase (que converte a tirosina em melanina) apresentando mudanças nas membranas dos melanócitos, aumentando a degradação dos melanossomas (RIBEIRO, 2010). O uso da HQ varia de 2 a 10\%, a concentração normalmente utilizada varia de 2 a 5\%, e para aplicação no tronco e extremidades de 6 a 10\% (MAIO, 2011).

Esse tratamento deve ser realizado a partir da associação de ativos com ácido retinóico, ácido glicólico e corticosteroides, esse tratamento deriva do benzeno que em alguns casos podem gerar efeitos colaterais, o uso prolongado pode ocasionar em acronose exógena (é uma dermatose, com características hiperpigmentantes de aspectos preto-azulados) (RIVAS et al., 2013; COSTA et al., 2010).

\section{Arbutin}

O arbutin, é um composto natural do extrato de plantas (uva), ingrediente ativo puro Biosintética, o mesmo é utilizado como clareador cutâneo utilizado no tratamento de hipercromias, quimicamente é um alfa-glicosídeo da hidroquinona e tem ação despigmentante por meio da inibição da tirosinase (Tyr). O tratamento promove um tom uniforme para todos os tipos de pele (GAEDTKE, 2011).

O clareamento é um ativo que atua de forma rápida e minimiza as manchas existentes, é indicado o uso de 1,0 a 3,0\% isoladamente em cremes, loções, géis e géis-cremes. Se for associado a outros despigmentantes, pode ser usado em concentrações menores, de 0,5 a 1,0\% (AREFIEV et al., 2012).

\section{Ácido Ascórbico ou vitamina C}

O ácido ascórbico ou a vitamina C é hidrossolúvel e faz parte de uma forma oxidada da glicose, $\mathrm{C} 6 \mathrm{H} 8$ $06(176,13 \mathrm{~g} / \mathrm{mol})$, sendo uma alfacetolactona de seis átomos de carbono, essa vitamina ajuda na redução de espécies reativas de oxigênio (MEDEIROS et al., 2016).

A principal função da Vitamina $C$ tem cobre e ferro reduzidos com antioxidantes hidrossolúveis que atuam em ambientes intra e extracelulares, com a hidroxilação do colágeno, da biossíntese da carnitina e da biossíntese de hormônios e aminoácidos (SHILS et al., 2009; FIGUEIRÓ et al., 2012). Esse tratamento contém fosfato de ascorbil magnésio (VC-PMG), proporciona clareamento da pele e a deixa mais leve, no decorrer da despigmentação é na fase de manutenção ou em combinação com outros despigmentantes (HOLLINGER et al 2018; SILVA et al., 2018). 


\section{Ácido Kójico}

O ácido Kójico é uma ativo microbiana, isolado de algumas espécies de Aspergillus, Penicillium e Acetobacter, obtido por fermentação do arroz. Tem a concentração de 1 a 3\%, potencializando os efeitos quando utilizados junto ao ácido glicólico, é uma substância fotossensível e estável que ajuda no clareamento cutâneo, impedindo a proliferação de fungos e bactérias na pele. É solúvel em água, etanol e acetona, não citotóxico, não irritante e não fotossensibilizante (FARIA et al., 2010).

Com base nas pesquisas e estudos realizados por Pontes et al. (2014), o Ácido Kójico é um dos despigmentantes mais utilizados e eficientes no tratamento do melasma, pois a mesma não causa irritação e fotossensibilização no paciente, além de ter a vantagem de ser usado com outros agentes, podendo ainda ser utilizado durante o dia.

Os efeitos do ácido kójico começam a se apresentar no decorrer de duas semanas quando usada diariamente no período de seis meses, os resultados dependem do fototipo, do tipo de pele e da localização do melasma, a concentração usual indicada é de 1 à $3 \%$ em veículos como cremes, emulsões fluidas não iônicas, géis, géis-cremes e loções aquosas (GONCHOROSK et al., 2015).Este ácido é útil para pacientes intolerantes à hidroquinona e pode ser combinado com um corticosteroide tópico para reduzir a irritação (MONTEIRO, 2015).

As características do ácido kójico são anti-irritante e não fotossensível, essa substância substitui o tratamento realizado com a hidroquinona, tornando o resultado com eficácia quando associado a ativos de ácido glicólico (BORGES, 2010).

\section{O Ácido Glicólico}

O ácido glicólico é composto por carbonos de um agrupamento hidroxila, na posição alfa, que não se alteram quando aplicadas na pele, o seu pH varia de 2,5 a 5, o tempo de resposta clínica depende de cada paciente e dos níveis de concentração na região aplicada. Quando o produto é aplicado acontece a dilatação dos vasos que diminuem a espessura da epiderme estimulando a produção do colágeno melhorando a absorção de outras substancias associadas sendo indicado para o envelhecimento, manchas hipercromias, rugas superficiais, acne e queratoses (MARQUES et al., 2016).

A aplicação do tratamento é indicada para todos os tipos de pele com afeitos positivos no tratamento de estrias, ceratoses actínias, melasma, acne, lesões de fotoenvelhecimento e rugas finas. O ácido glicólico é usado sob formulação em gel de 40 a $70 \%$ ou em soluções, sua utilização é indicada para todos os tipos de pele, mesmo que tenham acne, rugas e melasma. O ácido produz a compactação do estrato córneo, espessamento da epiderme e deposição de colágeno dérmico, aumentando a concentração e a diminuição do pH da formulação (KADUNC et al., 2012).

Para Sharad (2013) o ácido glicólico, usado para melhora do melasma, provocando a esfoliação da pele, diminuindo os efeitos colaterais da hidroquinona em pacientes que fazem uso desta terapia. 


\section{O Ácido Láctico}

O ácido láctico é mais suave e tem uma propriedade hidratante intrínseca logo após a aplicação seu componente natural funciona como umectante, esfoliante, com agente rejuvenescedor e clareador da pele com concentração superficial de $50 \%$. O ácido láctico e os lactatos (em quantidades acima de $5 \%$ ) dessa forma o efeito de formulações com pH 5,5 a 7,0 e seu pH tem uma variação entre 3,5 (quando se deseja um efeito esfoliante) a 5,5 (quando se deseja um efeito hidratante e clareador). Quanto maior for o pH, menor será a quantidade de ácido livre presente na formulação (com o pH ao redor de 5,5 praticamente todo o ácido já terá sido convertido à forma de lactato). $\mathrm{O}$ ácido lático pode não ser indicado para quem tem uma pele sensível (MAGALHÃES et al., 2014).

\section{Ácido Mandélico}

Ácido mandélico é derivado de amêndoas amargas que se conceituas dos alfa-hidroxiácidos (AHA'S) com peso molecular, sendo indicado para tratamentos de hiperpigmentação como despigmentaste em forma de peeling, proporcionando um efeito uniforme no local de aplicação. Sendo este um ácido seguro para ser utilizado em todos os tipos de pele, até a pele morena (BORGES, 2010).

Esse tratamento proporciona textura na pele, clareando as manchas e tratando as irregularidades. A molécula penetra além da camada córnea a atinge a derme proporcionando o tratamento preciso, promovendo uma descamação formando uma melanina na superfície da pele.

\section{O Ácido Tranexâmico}

Esse tratamento inibe a ativação da proteína responsável pela dissolução do colágeno. Promovendo uma estabilidade do colágeno o seu uso previne a pigmentação induzida pelos raios ultravioletas e o tratamento produz um clareamento rápido, entre 0,4 a $3 \%$. Sua ação não é pela atuação direta nos melanócitos, mas é através da inibição dos ativadores dos melanócitos, reduzindo a atividade da tirosinase (enzima chave na síntese da melanina) (SADIGURSKY et al., 2018).

\section{O microagulhamento}

Segundo Lima et al. (2015), o microagulhamento se associa a partir da permeação de ativos que disponibiliza bons tratamentos com baixo custo, e de fácil aplicação. O método utilizado contém uma média de 300 microagulhas, que medem de 0,5 a 3,0 cm de comprimento e 0,1 mm de diâmetro, que ao perfurar a pele gera micro perfusões ativando o processo inflamatório, produzindo metabolismo celular da derme e epiderme, estimulando o colágeno, de elastina com ácidos clareadores (LIMA et al., 2015).

O microagulhamento incentiva a formação do colágeno e elastina na derme reduzindo as manchas e cicatrizes após o tratamento, a ação remove a camada de células mortas da epiderme, estimulando a renovação tissular e promovendo melhorias no aspecto da pele (SOUSA, 2012). Estas lesões dirigem-se ao mesmo ponto na superfície onde inicia o processo de cicatrização natural e ocorre liberação de diversos 
fatores de crescimento, estimulando a migração e reprodução dos fibroblastos o que deposita uma maior quantidade de colágeno na pele (BERGMANN et al., 2015).

Laser

O laser é uma das opções de tratamento na prevenção do melasma e prevenção do envelhecimento precoce, ajuda na eliminação de edemas, estimulando o clareamento de manchas e elas, os lasers fracionados e ablativos estão sendo utilizados de forma esporádica no tratamento da melasma, mesmo não tendo comprovações científicas. O exato mecanismo de ação, tanto dos lasers ablativos quanto dos não ablativos, é ainda desconhecido, embora várias teorias tenham sido levantadas (STEINER et al., 2009). A utilização dos lasers pode diferir quanto ao tipo de meio ativador, à potência e dose utilizada e, também, quanto ao modo, tempo de irradiação e número de aplicações (BASHARDOUST et al., 2010; INOE et al., 2018).

Os tratamentos realizados com laser não são os suficientes para a eliminação total do melasma, contudo essa é uma terapia que quando aliada a outros processos tecnológicos alcançam resultados eficientes.

\section{Prevenção}

As causas da melasma ainda não foram elucidadas de forma clara e comprovada. Alguns fatores desencadeiam o aumento da melasma a partir da exposição solar, alimentação, doenças ovarianas, terapia de reposição hormonal, cosméticos, medicamentos fotossensibilizantes, processos inflamatórios da pele e eventos de estresse (MATOS et al., 2009). Hormônios sexuais como estrógenos e progestágenos estão relacionados ao surgimento do melasma. Gestação e terapia de reposição hormonal são os mais comumente referidos. Melasma é a melanodermia mais frequente em indivíduos de pele castanha a parda (HANDEL et al., 2014).

Existem várias formas terapêuticas que são recomendadas para o tratamento da melasma, incluindo a proteção solar, agentes despigmentantes tópicos, que atuam na inibição da atividade da tirosinase, remoção da melanina e destruição dos grânulos de melanina, e que com frequência incluem os tratamentos com hidroquinona ou outras substâncias, tais como ácido azelaico, tretinoína, alfa e beta-hidroxiácidos e corticoides tópicos usados como monoterapia ou em associação (ALTAEI, 2012; ARELLANO et al., 2012).Com base em Purim et al. (2012), a fotoproteção é conjunto sistemático de medidas que reduzem ou acentuam a exposição às radiações solares, prevenindo as consequências por meios químicos e físicos.

\section{CONCLUSÕES}

O Melasma diminui a autoestima e chega a ocasionar problemas psicossociais e vários tratamentos tem sido capaz de reduzir e tratar as manchas promovendo novas fibras de colágeno a partir da descamação, regeneração celular, dando origem a uma pele consistente, firme e com menos manchas de acordo com o tratamento pré e pós procedimento. Para o diagnóstico é necessário que o profissional se inteire da anatomia da pele, e como se dá o processo inflamatório, a melanogênese, e síntese de colágeno e elastina, é 
imprescindível para que se tenha resultados convincentes e longevos.

O tratamento da melasma quando realizado da forma correta clareia e da intensidade da hiperpigmentação reduzindo a extensão da área afetada, evitando a recidiva, melhorando a qualidade de vida do paciente. O uso sistemático de várias terapias tópicas com diferentes mecanismos de ação proporciona resultados que previnem retrocessos. Independente dos despigmentantes utilizado, a fotoproteção de amplo espectro é essencial para prevenir e formar uma nova melanina, existem várias terapias combinadas que podem tratar os melasma como (Peeling químicos e Laser, ou Microagulhamento e Peeling, ou Microagulhamento com ativos despigmentantes) e associações medicamentosas têm tendência a serem mais eficazes no tratamento do melasma com o uso da fotoproteção durante o dia-a-dia.

Dessa forma, esta revisão bibliográfica é de suma importância para a compreensão dos mecanismos pelos os quais os hormônios e a exposição aos raios UV induzem a síntese de melanina. É válido ressaltar que embora existam vários protocolos de tratamento do melasma a eficiência do tratamento é limitada em alguns casos se o paciente não manter uma forma sistemática de prevenção acontece a reincidência do melasma, no entanto é necessário que use protetor solar, que ajuda no bloqueio da radiação solar, uma vez que reduz a biossíntese, o transporte e transferência de melanina, conferindo redução da quantidade de melanina na pele.

\section{REFERÊNCIAS}

ACHAR, A.; RATHI, S. K.. Melasma: a clinico-epidemiological study of 312 cases. Indian J. Dermatol., v.56, p.380-382. 2011.

ALAM, M.; GLADSTONE, H. B.; TUNG, R. C.. Dermatologia Cosmética. Rio de Janeiro: Elsevier Ltda., 2010.

ALTAEI, T.. The treatment of melasma by silymarin cream. BMC Dermatology, v.12, n.18, 2012.

AMORIM, A. L. M.. Benefícios do peeling químico com ácido glicólico no processo de envelhecimento. 2014.

AREFIEV, K. L. B.; HANTASH, B. M.. Advances in the treatment of melasma: a review of the recent literature. Dermatol Surg., v.38, n.7, p.971-984, 2012.

ARELLANO, I.; CESTARI, T.; OCAMPO-CANDIANI, J.; AZULAYABULAFIA, L.; TRINDADE NETO, P. B.; HEXSEL, D.; MACHADOPINTO, J.; MUNHOZ, H.; RIVITTI-MACHADO, M. C.; SITTART, J. A., ALMEIDA, A. R. T.; REGO, V.; PALIARGUES, F.; MARQUES-HASSUN, K.. Preventing melasma recurrence: prescribing a mainten ance regimen with an effective triple combination cream based on long-standing clinical severity. Journal of the European Academy of Dermatology and Venereology, v.26, p.611-618, 2012.

AVRAM, M. R.; TSAO, S.; TANNOUS, Z.; AVRAM, M. M.. Atlas colorido de Dermatologia Estética. Rio de Janeiro: McGrawHill Interamericana do Brasil, 2018.

BASHARDOUST, T. S.; MACDERMID, J. C.; HOUGHTON, P.; GREWAL, R.. Effects of low power laser irradiation on bone healing in animals: a metaanalysis. J. Orthop Surg Res., v.5, p.1-13, 2010.
BECKER, S.; SCHIEKOFER, C.; VOGT, T.; REICHRATH, J.. Melasma: Ein Update zu Klinik, Therapie und Pravention. Der Hautarzt., v.68, p.120-126, 2017.

BERGMANN, C. L. M. S.; BERGMANN, J.; SILVA, C. L. M.. Melasma e Rejuvenescimento Facial com uso de peeling de ácido retinóico a $5 \%$ e microagulhamento: caso clínico. 2015.

BORGES, F.. Dermato-funcional, modalidades terapêuticas nas disfunções estéticas. 2 ed. São Paulo: Phorte, 2010.

BRIANEZI, G.. Avaliação da atividade da unidade epidermomelânica e do dano dérmico no melasma. Tese (Doutorado em Patologia) - Universidade Estadual Paulista "Júlio de Mesquita Filho", Botucatu, 2016.

CAETANO, T. M.; OLIVEIRA, S. P.. Tratamento de melasma com ácido mandélico em fototipos elevados. Curitiba: Universidade Tuiuti do Paraná, 2013.

CESTARI, T. F.; DANTAS, L. P.; BOZA, J. C.. Acquired hyperpigmentations. An Bras. Dermatol, v.89, p.11-25, 2014.

COSTA, A.; MOISÉS, T. A.; CORDERO, T.; ALVES, C. R. T.; MARMIRORI, J.. Associação de emblica, licorice e belides como alternativa à hidroquinona no tratamento clínico do melasma. An. Bras. Dermatol., Rio de Janeiro, v.85, n.5, p.613-620, 2010.

D'ELIA, M. P. B.. Avaliação comparativa da ancestralidade em mulheres com melasma facial: um estudo transversal. Dissertação (Mestre em Patologia) - Faculdade de Medicina, 
Universidade Estadual Paulista "Júlio de Mesquita Filho", Botucatu, 2015.

DAYAL, S.; SAHU, P.; YADAV, M.; JAIN, V.. Eficácia Clínica e Segurança na Combinação de Peeling de Ácido Tricloroacético a 20\% com Ácido Ascórbico 5\% Tópico para Melasma. Jornal de Pesquisa Clínica e Diagnóstica, v.11, n.9, p.WC08-WC112017.

FARIA, K. S. S.; LUBI, N.. A utilização do Ácido Kojico no tratamento de melasma. 2019.

FIGUEIRÓ, T. L.; FIGUEIRÓ FILHO, E. A.; COELHO, L. K.. Pele e gestação aspectos atuais dos tratamentos e drogas comumente utilizados. Feminina, v.36, n.8, p.511-521, 2012.

GAEDTKE, N. G.. Abordagem Terapêutica do Melasma na Gestação: Revisão Bibliográfica. Dissertação (Mestrado em Medicina Estética) - Universidade Tuiuti do Paraná, Curitiba, 2011.

GIL, A. C.. Métodos e técnicas de pesquisa social. 5 ed. São Paulo: Atlas, 2010.

GONCHOROSK, D. D.; CÔRREA, G. M.. Tratamento de hipercromia pós-inflamatória com diferentes formulações clareadoras. Infarma, v.17, p.84-88, 2015.

HABIF, T. P.. Dermatologia clínica. Guia colorido para diagnóstico e tratamento. Rio de Janeiro: Elsevier, 2012.

HANDEL, A. C.; MIOT, L. D. B.; MIOT, H. A.. Melasma: a clinical and epidemiological review. An. Bras. Dermatol., v.89, p.771-782, 2014.

HEXSEL, D.; LACERDA, D. A.; CAVALCANTE, A. S.; MACHADO FILHO, C. A.; KALIL, C. L.; AYRES, E. L.. Epidemiology of melasma in Brazilian patients: a multicenter study. Int J. Dermatol., v.53, p.440-444. 2013.

HOLLINGER, J. C.; ANGRA, K.; HALDER, R. M.. Ingredientes naturais são eficazes na gestão da hiperpigmentação? Uma revisão sistemática. 0 Jornal de Dermatologia Clínica e Estética, v.11, n.2, p.28-37, 2018.

INGBER, A.. Hyperpigmentation and Melasma. Obstetric Dermatology, v.3, p.7-18, 2009.

INOE, A. P.; ZAFANELLI, C. C. G.; ROSSATO, R. M.; LEME, M. C.; SANCHES, A. W. D.; ARAÚJO, C. V.. Avaliação morfológica do efeito do laser de baixa potência He-Ne em feridas cutâneas de coelhos. Arq Ciênc. Vet Zool Unopar., v.11, n.1, p.27-30, 2018.

KADUNC, B.; ADDOR, F.; MATTOS, R.. Tratado de cirurgia dermatológica, cosmiatria e laser. Rio de Janeiro: Elsevier, 2012.

LIMA, A. A.; SOUZA, T. H.; GRIGNOLI, L. C. E.. Os benefícios do microagulhamento no tratamento das disfunções estéticas. Revista Científica da FHO, Araras, v.3, n.1, p.9299, 2015.

MAGALHÃES, G. M.; BORGES, M. F. M.; OLIVEIRA, P. J. V.; NEVES, D. R.. Peeling de ácido lático no tratamento do melasma: avaliação clínica e impacto na qualidade de vida. Surgical Cosmetic Dermatology, v.2, p.173-179, 2010.
MAIO, M.. Tratado de Medicina Estética. 2 ed. São Paulo: Roca, 2011.

MARQUES, J.; TOMAZONI, R. C.; FRANÇA, A. J. V. B. V.. O uso do peeling de ácido glicólico no tratamento da pele foto danificada. Monografia (Bacharelado) - Universidade do Vale do Itajaí, Itajaí, 2016.

MASCENA, T. C. F.. Melasma e suas principais formas de tratamento. Monografia (Especialização em Biomedicina Estética) - Instituto de Ensino Superior e Pesquisa Centro de Capacitação Educacional, Recife, 2016.

MATOS, M. G. C.; CAVALCANTI, I. C.. Melasma. In: KEDE, M. P. V.; SABATOVICH, O.. Melasma. Dermatologia estética. 2 ed. São Paulo: Atheneu, 2009.

MEDEIROS, J. K. G. M.; NEVES, W. W.; MOURA, N. M.; MEDINA, W. S. G.. Combinação terapêutica no tratamento do melasma. Rev. CuidArte Enfermagem, v.10, n.2, p.180187, 2016.

MIOT, L.; SILVA, M. G.; MIOT, H. A.; MARQUES, M. E. A.. Fisiopatologia do melasma. An Bras. Dermatol., v.84, n.6, p.623-635, 2009.

MONTEIRO, E. O.. Melasma: abordagem tópica. 2015.

NEVES, P. B.. Revisão de literatura sobre melasma: Enfoque no tratamento. Tese (Doutorado) - Instituto de Ciências da Saúde, Alfenas, 2013.

NICOLAIDOU, E.; KATSAMBAS, A. D.. Pigmentation disorders: hyperpigmentation and hypopigmentation. Clinics in Dermatology, v.32, p.66-72, 2014.

PONTES, C. G.; MEJIA, D. P. M.. Ácido Kójico no tratamento do melasma. 2014.

PURIM, K. S. M.; AVELAR, M. F. S.. Fotoproteção, melasma e qualidade de vida em gestantes. Rev. Bras. Ginecol. Obstet., v.34, n.5, p.228-34, 2012

RIBEIRO, C.. Cosmetologia aplicada a dermoestética. 2 ed. São Paulo: Pharmabooks, 2010.

RIVAS, S.; PANDYA, A. G.. Treatment of melasma with topical agents, peels and lasers: an evidence-based review. Am J. Clin Dermatol., v.14, n.5, p.359-376, 2013.

RODRIGUES, B.. Estudo comparativo do tratamento da hiperpigmentação utilizando ativos cosméticos e eletroterapia. Monografia (Tecnóloga em Estética e Cosmética) - Universidade de Santa Cruz do Sul, Santa Cruz do Sul, 2016.

SADIGURSKY, D.; ARAUJO, L. M.; FERNANDES, R. J. C. Efficacy of tranexamic acid in reducing blood loss in total knee arthroplasty. Acta Ortop. Bras., São Paulo, v.26, n.1, p.63-66, 2018.

SANDIN, J.; OLIVEIRA, T. G.; CURI, V. C.; MACEDO, A. C. L.; SAKAI, F. D. P.; VASCONCELOS, R. C. F.. Aplicação de peeling de ácido lático em pacientes com melasma: um estudo comparativo. Surg. Cosmet. Dermatol., v.6, p.255-260, 2014. 
SARKAR, R.; CHUGH, S.; GARG, V. K.. Terapias mais recentes e futuras para o melasma. Indian J. Dermatol Venereol Leprol., v.78, p.417-28, 2012.

SHARAD, J.. Glycolic acid peel therapy: a current review. Clinical, Cosmetic and Investigational Dermatology, v.6, p.281-288, 2013.

SHILS, M. E.; SHIKE, M.; ROSS, A. C.; CABALLERO, B.; COUSINS, R. J.. Nutrição moderna na saúde e na doença. 10 ed. São Paulo: Manole, 2009.

SILVA, R. S.; OLIVEIRA, F. V. B.; SOARES, M. T. S.; SILVA, D. P. F.; SALES, S. C.; MELO, C. S.. Eficácia do tratamento com Ácido Ascorbico (Vitamina C) no clareamento do melasma: Uma Revisão Literária. Rev. Interdisciplinar de Ciências Medicas, Teresina, 2018.

SOUSA, P. M.. A atuação do biomédico em procedimentos estéticos não invasivos e invasivos não-cirúrgicos. 2012.
SOUZA, V. M.; ANTUNES JUNIOR, D.. Ativos dermatológicos. São Paulo: Tecnopress, 2012.

STEINER, D.; FEOLA, C.; BIALESKI, N.; SILVA, F. A. M.; ANTIORI, A. C. P.; ADDOR, F. A. S.'A.; FOLINO, B. B.. Estudo de avaliação da eficácia do ácido tranexâmico tópico e injetável no tratamento do melasma. Surg. Cosmet. Dermatol., v.1, n.4, p.174-177, 2009.

TAMEGA, A. A.; MIOT, L. D.; BONFIETTI, C.; GIGE, T. C.; MARQUES, M. E.; MIOT, H. A.. Clinical patterns and epidemiological characteristics of facial melasma in Brazilian women. J. Eur Acad Dermatol Venereol., v.27, p.151-156, 2013.

YOKOMIZO, V. M. F.; BENEMOND, T. M. H.; CHISAKI, C.; BENEMOND, P. H.. Peelings químicos: revisão e aplicação prática. Surgical \& Cosmetic Dermatology, v.5, n.1, p.58-68, 2013.

A CBPC - Companhia Brasileira de Produção Científica (CNPJ: 11.221.422/0001-03) detém os direitos materiais desta publicação. Os direitos referem-se à publicação do trabalho em qualquer parte do mundo, incluindo os direitos às renovações, expansões e disseminações da contribuição, bem como outros direitos subsidiários. Todos os trabalhos publicados eletronicamente poderão posteriormente ser publicados em coletâneas impressas sob coordenação da Sapientiae Publishing, da Companhia Brasileira de Produção Científica e seus parceiros autorizados. Os (as) autores (as) preservam os direitos autorais, mas não têm permissão para a publicação da contribuição em outro meio, impresso ou digital, em português ou em tradução. 